\title{
Measurement of The Muscle Fitness Level of 9-12 Years Old Badminton Players with The Kraus Weber Method
}

\author{
Dinan Mitsalina \\ Master Program in Sport Sciences \\ Universitas Negeri Yogyakarta \\ Yogyakarta, Indonesia \\ dmitsalina@gmail.com
}

\author{
Widiyanto \\ Faculty of Sport Sciences \\ Universitas Negeri Yogyakarta \\ Yogyakarta, Indonesia \\ widi@uny.ac.id
}

\begin{abstract}
-badminton is a sport that requires muscle fitness and good flexibility to reduce risks of injury due to the intense characteristics of the sport (high impact, high intensity, and multi-directionality). This research aims to measure the level of muscle fitness of 9-12-year-old badminton players. The Research subjects are badminton players aged 9-12 years in a club in Yogyakarta, Indonesia comprised of 12 female and male athletes. The Kraus Weber test was the technique used to collect data. The Research shows that the worst muscle fitness level of badminton players aged 9-12 years is found around the abdominal muscle, which is dominated by all male athletes in the obesity category. Great badminton players between the ages of 9-12 years have back muscle strength and spine flexibility, and good hamstring muscles. This method is effective for measuring muscle fitness of early athlete in various sports.
\end{abstract}

Keywords—muscle fitness, badminton, Kraus Weber

\section{INTRODUCTION}

Badminton is a sport with a high risk of sustaining injury due to the features of its gameplay (high impact, high intensity, and multi-directionality) [1]. During gameplay, the most commonly incurred injury is from the lower extremities (pelvis, knee, ankle, and back). Fitness, and flexibility, and good muscle tone are major factors for preventing injuries. Inadequacy of these factors increases the risk of injury, and decreases athletes' game time and achievement. The poor muscle condition in athletes is as a result of lack of proper training methods by the trainer. If this is not corrected from an early age, and severe training continues, it may result to an injury. Muscle fitness is a combination of muscle strength and muscle endurance [2].

The level of muscle fitness can be measured using sit ups, legs and back dynamometers, Harvard step tests, vertical jumps, and so on. The flexibility of spinal joints and hamstring muscles can be measured using the sit and reach test. The Kraus Weber method was used in this research to measure the muscle strength, spinal flexibility and the hamstring muscle. This test was created by Hans Kraus and Hirschland in 1953, at the time of creation it was used to measure the minimum muscle fitness of elementary school children in the United States and Europe [3]. This method is conveniently done by children, minimal energy, time, and cost. Furthermore, the procedure does not require any special equipment. This test consists of five items of the strength test and one from the flexibility test. The procedure was carried out by measuring the strength level in the core muscles (back muscles, waist muscles, abdominal muscles, psoas muscles or pelvic flexor muscles) and measuring the flexibility of the spinal joints and hamstring muscles [4]. The ability or the inability of the subject to take the Kraus Weber test will be an evaluation component. In previous studies, muscle fitness measurements in athletes especially in early aged athletes has not been conducted, this led to the current research on the athletes within the age of 9-12 in Yogyakarta, Indonesia.

\section{METHODS}

The research sample were all members of a badminton club in Yogyakarta, Indonesia with the age range of 9-12 years, amounting to 12 players (10 males and 2 females) and was done based on consideration. The sample inclusion criteria were; 9-12 year-old children registered as club members, routinely attended the exercise at least 2 times a week, declared eligible for research, and obtained consent from the parent or guardian. The methods and Instruments used in this research were the Kraus Weber test, staturmeter (height measuring instrument), weight scales, stopwatch, stationery, and towels. During the early stages, personal data of the club members were recorded, such as name, address, age, gender, contact person, height, weight, and so on. Body height and weight are used to calculate the Body Mass Index $(B M I)=W e i g h t /(\text { Height })^{2}$, then the results were categorized according to the Anthropometric Standards Assessment of Nutritional Status of Children by Decree of the Minister of Health of the Republic of Indonesia in 2011.

TABLE I. DATA RETRIEVAL BY USING KRAUS WEBER TEST WAS PERFORMED

\begin{tabular}{|c|c|c|}
\hline Index & Category & Threshold(Z-Score) \\
\hline \multirow{4}{*}{$\begin{array}{c}\text { (IMT/U) } \\
\text { 5-18-year-old children }\end{array}$} & Very thin & $<-3$ SD \\
\cline { 2 - 3 } & Thin & -3 SD to <-2 SD \\
\cline { 2 - 3 } & Normal & -2 SD to 1 SD \\
\cline { 2 - 3 } & Fat & $>1$ SD to 2 SD \\
\cline { 2 - 3 } & Obese & $>2$ SD \\
\hline
\end{tabular}


Description of Kraus Weber Test:

a) Abdominal and psoas muscles

Subjects lie on their backs against the floor with both legs straight attached to the floor. Both hands are placed behind the neck. The tester holds both ankles off. The subject lifts the body to a full sitting position without bending the knee.

b) Abdominal muscle without the psoas muscle Subjects lie on their backs against the floor with both knees bent at $90^{\circ}$. Both of subject's hands are placed behind the ear. The tester holds both ankles off. The subject lifts the body to a full sitting position.

c) Psoas Muscles (lower abdomen)

Subjects lie on their backs, both legs are straight. Both hands behind the neck. The subject lifts both legs in a straight position with an angle of $30^{\circ}$ or with a distance of $25 \mathrm{~cm}$ from the floor.

d) Upper back muscles

Subjects lie prone with both hands behind the neck and both legs straight. A pillow is placed on the lower abdomen and groin, the pillow is positioned quite high from the floor to produce a seesaw effect. The Tester holds both limbs of the subject so that both limbs are not lifted. Subjects raise their chest, shoulders, and heads from the floor. The position is held for 10 seconds.

e) Waist muscles

Subjects lie prone with both hands behind the neck and both legs straight. A pillow is placed on the lower abdomen and groin, the pillow is positioned rather high from the floor to give the effect of seesaw. The Tester holds both limbs of the subject to ensure both limbs are not lifted. The subject lifts both legs in a straight position without bending the knee. The position is held for 10 seconds.

f) Flexibility of the spine and hamstring muscles

Subject stands perpendicular (anatomical position) and bends slowly till fingertips can touch the floor. Their knees are kept straight. When touching the floor they should not bounce. The position is held for 10 seconds.
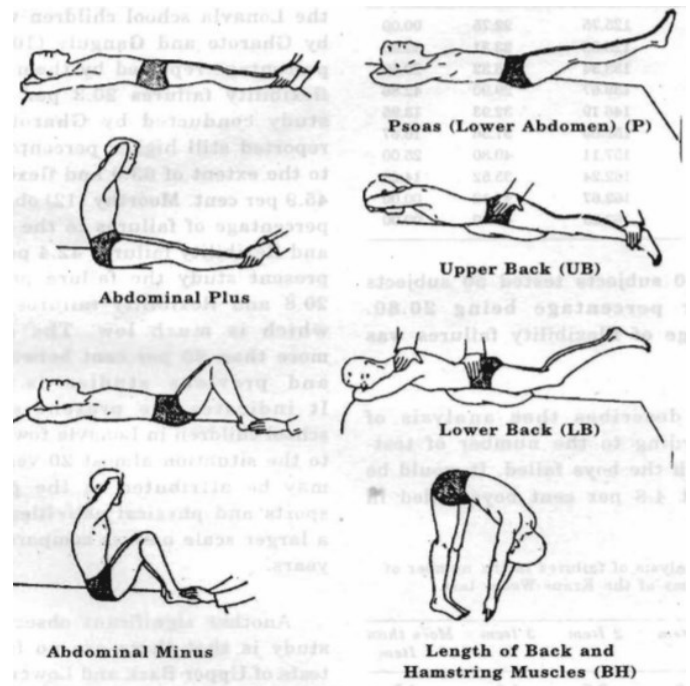

Fig. 1. Kraus Weber Test
The test result data were collected and recorded, then analyzed and recommended, before conclusions were drawn from the data processing results. The ability or the inability of the subject to take the Kraus Weber test will be a valuation component. The Data analysis used the descriptive statistics and percentages

\section{RESUlT AND DISCUSSION}

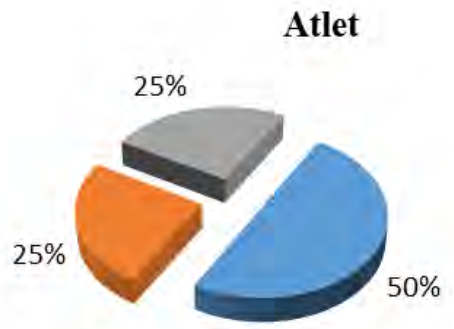

Normal

Gemuk

Obesitas

Fig. 2. Number of Players Based on Body Mass Index

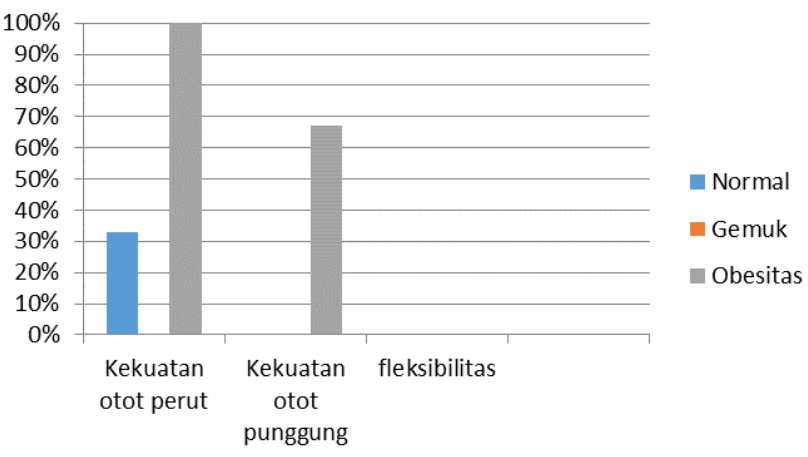

Fig. 3. Kraus Weber Test Failure Based on IMT

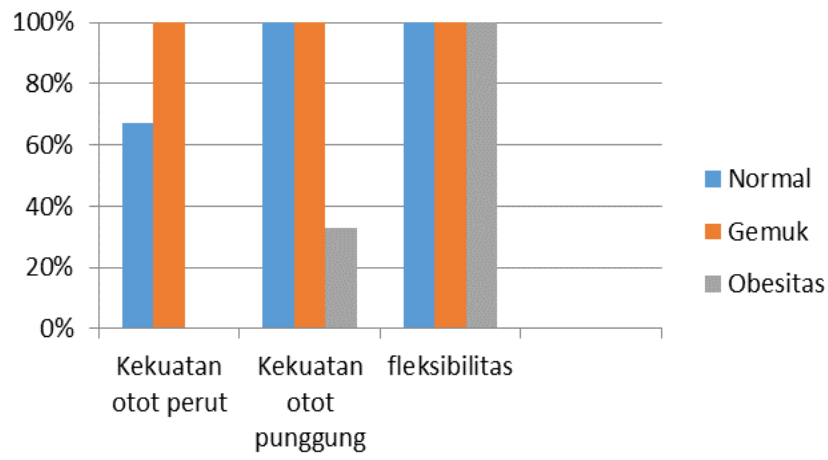

Fig. 4. Kraus Weber Test Success Based on IMT 


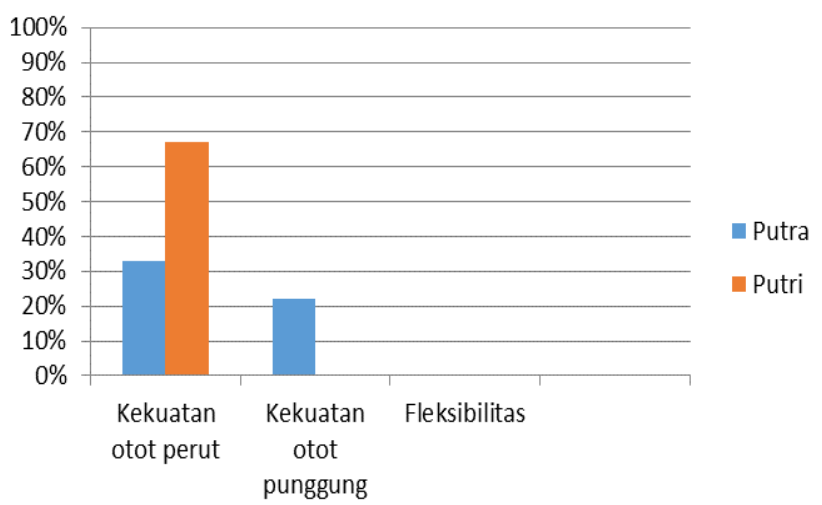

Fig. 5. Kraus Weber Test Failure Based on Sex

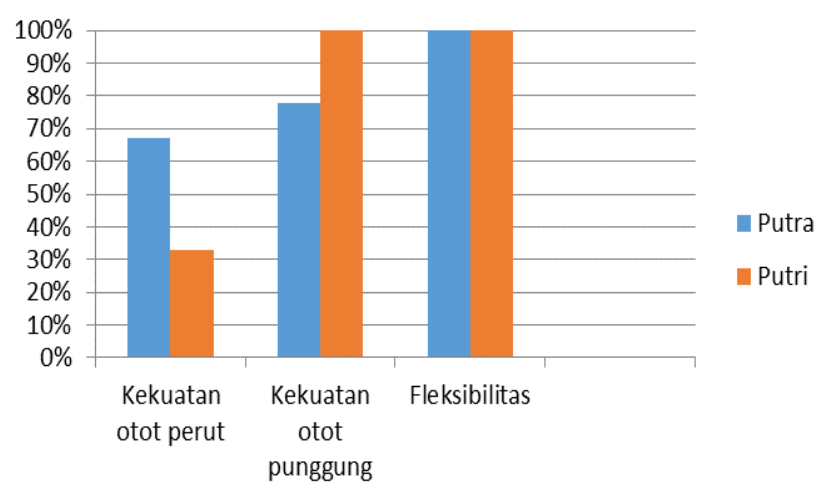

Fig. 6. Kraus Weber Test Success Based on Sex

Based on the survey above, most test failures were recorded in abdominal muscle strength tests (test 2 and test 3 ) with 3 people for test 2 and 3 people for test 3 . Test 2 was a test for measuring abdominal muscle strength without psoas muscle and test 3 was for measuring the strength of lower abdominal muscles with psoas muscles. In badminton as a sport, the iliopsoas muscle plays an important role in the movement of jumping smash (twisting movement), movement to various directions (multi direction), and lunges [6].

All players with a Body Mass Index of the obese category were 3 males and they failed in the abdominal muscle strength tests. This research [7] shows that the average badminton player has a normal Body Mass Index. Badminton players with normal body mass index are advantaged based on the high physiological demands of badminton games. So, athletes from an early age need to pay attention to the Body Mass Index to remain in the normal category. The results also show that badminton players have bad abdominal muscle strength. In male badminton players, the most common test failure recorded was on the abdominal muscle strength without the psoas muscle (test 2) which amounted to 3 people. In the female category, the failure was found in the test of the lower abdominal muscle strength with psoas muscle (test 3 ). All athletes could successfully perform test 4 and test 6 according to the procedure. Test 4 was a test to measure upper back muscle strength and test 6 was to measure the flexibility of the spinal joints and hamstring muscles. This indicates that badminton players have upper back muscle strength and good flexibility.

Athletes can have good muscle fitness and flexibility and can cut down the risks of injury if they train regularly from an early age with proper training techniques and programs highly trained and accredited trainers through the national accreditation systems dealing with appropriate sports organizations [8].

\section{CONCLUSION}

From the research above, it can be concluded that the worst level of muscle fitness is the abdominal muscle strength which was dominated by all male players in the obese category. All players have good back muscle strength and spine flexibility, and good hamstring muscles. The results of this research can be used as a reference material for trainers of various sports to correct and improve training methods as early as possible so sportsmen do not train on the wrong path and can provide a variety of trainings aimed at improving muscle fitness levels of athletes.

\section{REFERENCES}

[1] B. Chen, "High Intensity Stepwise Conditioning Programme for Improved Exercise Responses and Agility Performance of a Bad Player with Knee Pain,” J. of Physical Therapy in Sport. 2015. 80-85.

[2] Ortega, "Childhood and Adolescence: A Powerful Marker of Health." International Journal of Obesity. 2008. 1-11.

[3] Rawat. "Minimum Muscular Fitness and Ventilatory Function South Indian School Children," Journal of Public Health. 2014. 104-116.

[4] Kulkarni. "Assessment of Muscular Fitness In School Children Using Kraus-Weber Tests," Journal of Public Health. 2010. 30-35.

[5] Corlett. "Minimum Muscular Fitness of Urban Tswana Children," Child: care, health, and development. 37-43. 1985.

[6] Qichang. "A Biomechanical Investigation of Right-Forward Lunging Step among Badminton Players," J. of Sports Sciences. 2016. 1-6.

[7] Laffaye. "The Science of Bad: Game Characteristics, Anthropometry, Physiology, Visual Fitness, and Biomechanics," Journal of Sports Medicine. 2014. 4-26.

[8] Sidik, Giriwijoyo. Ilmu Kesehatan Olahraga, Bandung: PT Remaja Rosdakarya. 2012. 